\title{
Care for unplanned extubation prevention: analysis of the validity of an instrument's content
}

\author{
Cuidados para prevenção de extubação não planejada: análise da validade do conteúdo de um instrumento \\ Cuidado para la prevención de la extubación no planificada: análisis de la validez del contenido de un instrumento
}

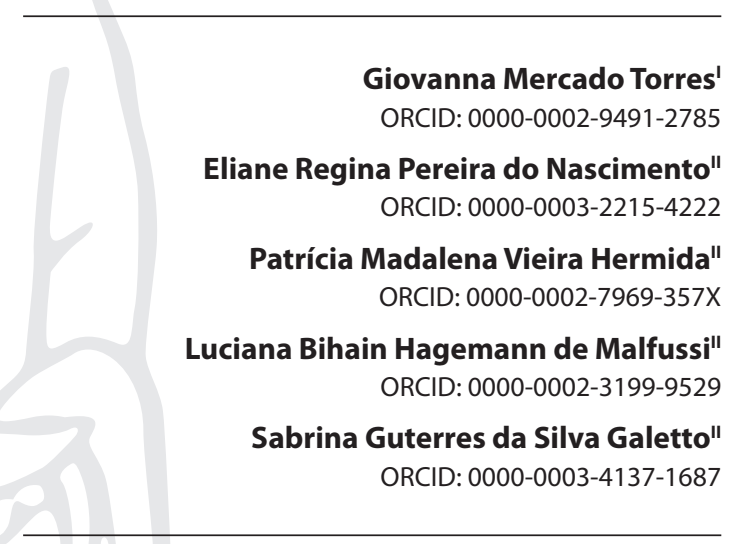

'Hospital Cayetano Heredia. Lima, Peru. "Universidade Federal de Santa Catarina. Florianópolis, Santa Catarina, Brazil.

How to cite this article: Torres GM, Nascimento ERP, Hermida PMV, Malfussi LBH, Galetto SGS. Care for unplanned extubation prevention: analysis of the validity of an instrument's content.

Rev Bras Enferm. 2021;74(1):e20180998. doi: http://dx.doi.org/10.1590/0034-7167-2018-0998

Corresponding author:

Giovanna Mercado Torres E-mail:vannia_27@yahoo.es

EDITOR IN CHIEF: Dulce Barbosa ASSOCIATE EDITOR: Marcia Magro

Submission: 02-22-2019

Approval: 09-07-2020

\section{ABSTRACT}

Objectives: to analyze the validity of a nursing care instrument content for unplanned extubation prevention in Intensive Care Units. Methods: a methodological study carried out with 40 nurses, containing 26 interventions distributed in the components: agitation/delirium/ pain management; respiratory device stability; weaning from sedation and spontaneous breathing assessment; human resource management. Content Validity Index, average and universal proportion, and Fleiss' Kappa coefficient were applied. Results: Brazilian female experts stood out, with an average age of 44.9 years and a standard deviation of 7.75 years. Two interventions did not reach a valid Content Validation Index $(\geq 0.78)$, when considering the set of evaluated criteria. A universal agreement of $4.0 \%$ was identified among Brazilians and $26.6 \%$ among foreigners. Conclusions: the instrument is relevant and represents "unplanned extubation prevention in Intensive Care Units", which can be implemented in Brazil and in Latin countries, in Brazilian and foreign versions.

Descriptors: Critical Care; Airway Extubation; Intensive Care Units; Patient Safety; Validation Study.

\section{RESUMO}

Objetivos: analisar a validade do conteúdo de um instrumento de cuidados de enfermagem para prevenção de extubação não planejada em Unidade de Terapia Intensiva. Métodos: estudo metodológico, com 40 enfermeiros, contendo 26 intervenções distribuídas nos componentes: gestão da agitação/delirium/dor; estabilidade do dispositivo respiratório; desmame da sedação e avaliação da respiração espontânea; gestão de recursos humanos. Aplicou-se Índice de Validade de Conteúdo, proporção média e universal, e Coeficiente Kappa. Resultados: destacaram-se especialistas brasileiros, femininos, com idade média de 44,9 anos e desvio padrão de 7,75 anos. Duas intervenções não atingiram Índice de Validação de Conteúdo válido $(\geq 0,78)$, quando considerado o conjunto dos critérios avaliados. Identificou-se acordo universal de $4,0 \%$ entre os brasileiros e de $26,6 \%$ entre os estrangeiros. Conclusões: o instrumento é relevante e representa o conteúdo "prevenção de extubação não planejada em Unidade de Terapia Intensiva", podendo ser implementado no Brasil e em países latinos, nas versões brasileira e estrangeira.

Descritores: Cuidados Críticos; Extubação; Unidades de Terapia Intensiva; Segurança do Paciente; Estudos de Validação.

\section{RESUMEN}

Objetivos: analizar la validez de contenido de un instrumento de cuidados de enfermería para la prevención de extubación no planificada en una Unidad de Cuidados Intensivos. Métodos: estudio metodológico, con 40 enfermeras, conteniendo 26 intervenciones distribuidas en los componentes: manejo de la agitación/delirio/dolor; estabilidad de dispositivo respiratorio; destete de la sedación, evaluación de la respiración espontánea; gestión de recursos humanos. Se aplicaron Índice de Validez de Contenido, proporción media y universal y Coeficiente Kappa. Resultados: destacaron las especialistas brasileñas, con edad promedio de 44,9 años, y desviación estándar de 7,75 años. Dos intervenciones no alcanzaron un Índice de Validación de Contenido válido $(\geq 0,78)$, al considerar el conjunto de criterios evaluados. Se identificó concordancia universal de $4.0 \%$ entre brasileños y $26.6 \%$ entre extranjeros. Conclusiones: el instrumento es relevante y representa el contenido "prevención de extubación no planificada en una Unidad de Cuidados Intensivos", que puede ser implementado en Brasil y en países latinos, en versiones brasileñas y extranjeras. Descriptores: Cuidados Críticos; Extubación Traqueal; Unidades de Cuidados Intensivos; Seguridad del Paciente; Estudio de Validación. 


\section{INTRODUCTION}

Critical care environments, such as Intensive Care Units (ICUs), predispose to the occurrence of adverse events (AE), multi-causal phenomena related to the critical environment, to performance of numerous invasive procedures, use of dense technology and medical equipment, in addition to patients' clinical peculiarities ${ }^{(1)}$.

$\mathrm{AE}$ is understood as the occurrence of incidents that result in damage to patients ${ }^{(2)}$, resulting from the care provided, and not attributed to the natural progression of the underlying disease, such as pressure injuries, phlebitis, falls and unplanned extubation (UPE).

UPE is defined by premature orotracheal tube (OTT) removal due to the action of mechanically ventilated patients (selfextubation), or premature removal during medical and nursing care (accidental extubation) ${ }^{(1)}$, as in bathing situations, intra transport or extra-hospital, change of position and replacement of OTT fixation ${ }^{(3)}$

A literature review study ${ }^{(4)}$ reported complications resulting from UPE related to airway management, respiratory and hemodynamic problems, prolongation of hospital stay and time on mechanical ventilation (MV). Other studies ${ }^{(5-6)}$ identified difficult reintubation, increased rates of infections and increased mortality of patients in ICUs.

The literature supports some strategies to cope with this $\mathrm{AE}$ such as increased interprofessional communication ${ }^{(7)}$, workload optimization, adequate nurse/patient relationship and adoption of UPE protocols ${ }^{(4)}$. Despite this, it is known instruments use such as guidelines, bundles and checklists, associated with training and permanent education of professionals are pillars of patient safety ${ }^{(8-9)}$; these specific instruments allow nurses and other professionals to make better care choices and possibilities for quality of life ${ }^{(10)}$.

In this regard, a care instrument for UPE prevention was built under three main points: care with OTT (appropriate length, secure fixation, verification of regular position and rapid response to displacement), sedation (appropriate choice and depth) and spontaneous tests of awakening and breathing. Its implementation in an ICU of a Cardiothoracic Center in the United Kingdom was associated with a significant reduction in UPE ${ }^{(11)}$. In a similar context, there was also a significant improvement in the UPE rate, due to standardization processes, intensive team education and changing the unit's culture for constant surveillance ${ }^{(12)}$.

Given the above, considering the increased occurrence of UPE perceived by the nursing staff of an ICU located in Lima, Peru, and non-location in literature databases pertinent to instrument use to prevent UPE, especially in South America, a nursing care instrument for UPE prevention was developed, which was submitted in the present study to content validation by experts from six Latin American countries.

\section{OBJECTIVES}

To analyze the validity of a nursing care instrument content for UPE prevention in ICUs.

\section{METHODS}

\section{Ethical aspects}

This study was approved by the Research Ethics Committee of Universidade Federal de Santa Catarina,. Among the ethical care for both Brazilian and foreign participants, patient anonimity was considered as well as the right to withdraw from the research at any time without any loss and the guarantee of not having to pay for participation.

All participants signed the Informed Consent Form (ICF). For foreigners, the term was evaluated by the head of academic and ethical affairs of the Latin-American Federation of Intensive Care Nurses (FLECI) and adapted to Spanish, in compliance with the ethical standards of this organization.

\section{Design, place of study and period}

This is a methodological study to validate the instrument's content based on the agreement of a committee of expert nurses (judges) in the intensive care field. This study covered six South American countries participating in $\mathrm{FLECl}$, such as Argentina, Brazil, Chile, Paraguay, Peru, and Uruguay. The six countries were chosen because they are an entity with recognized prestige that brings together researchers and professors of intensive care nurses from South America, who develop works related to the theme of the study. Data collection was carried out between August and October 2017.

\section{Population and sample}

Fourty intensive care experts participated in this study, being 25 Brazilians and 15 foreigners. By judgment, the experts who reached the minimum score of six and maximum of 20 points in resume assessment were selected following the established criteria ${ }^{(13)}$, namely: clinical experience in the field (four points), in teaching (one point), in research (one point), participation in research groups (one point), post-doctorate degree (two points), master's degree (one point) and residency in a specific field (one point), reaching 104 nurses. Resumes updated more than 24 months ago were excluded.

The operation to identify potential judges took place through the Curriculum Lattes platform of the Brazilian National Council for Scientific and Technological Development (CNPq - Conselho Nacional de Desenvolvimento Científico e Tecnológico) using advanced search tool by subject (intensive care unit/intensive care unit/critical care unit/critical care), and in the bases: doctors and other researchers, nationality: Brazilians and foreigners.

The filter was applied: academic training/degree: doctorate, master's, specialization; professional performance: major area: health sciences; area: nursing; subarea: adult and elderly health nursing. Preferences: curriculum update time: 24 months. In order to identify possible foreign judges, in addition to search on the Curriculum Lattes platform, the main researcher contacted FLECI, who nominated names of experts and their contacts.

Brazilian and foreign judges were accessed by the main researcher by email, by means of an invitation letter, stating the 
objectives, justification and validation procedure. The instrument was also sent in its entirety and the ICF. Thus, each assessment form was answered individually. After accepting participation and signing the term, a period of 15 days was requested to return the instrument.

\section{Study protocol}

A care instrument was constructed involving semi-structured interviews about care by professionals in UPE prevention and discussion group (DG). Sixteen ICU nursing professionals from a public hospital in Peru participated in the interview. All care/ procedures were grouped by similarity in four components: Agitation/delirium/pain management; Respiratory device stability; Weaning from sedation and spontaneous breathing assessment; Human resource management. Quality assessment and classification of evidence of care was carried out according to Grading of Recommendation Assessment, Development and Evaluation (GRADE) (14).

The DG took place in two meetings, with the participation of nine professionals. The DG aimed to present the data from the previous phase and select a care of each component to constitute the instrument, considering the local reality. It was decided, after discussion, that the instrument would consist of 26 care/interventions.

The instrument was submitted to content validation, made available to the judges through an electronic form via web, built in two parts: the first part refers to personal data such as age and sex, professional data (training, specialization and other graduate levels) and labor data of participants; the second part has guidance for filling it out and the modified Pasquali validation criteria (pertinence, consistency, clarity, objectivity, simplicity, feasibility, and accuracy $)^{(15)}$, which were applied in the study.

In the end of the instrument, there was a space to justify the reason why a participant was chosen and make comments and suggestions. It is worth mentioning that, for foreign judges, the instrument was made available in Spanish, freely translated by one of the researchers, whose native language is Spanish. The judges used a four-point Likert scale to assess all items, namely: there is no criterion (one point); unable to have the criterion without review (colon); has the criterion, but needs a minimum change (three points); has the criterion (four points) ${ }^{(16)}$.

\section{Analysis of results, and statistics}

The data obtained were organized and analyzed using Microsoft Excel, 2010. The Content Validity Index (CVI) was applied to each intervention according to each of the assessed criteria. The care instrument's CVI as a whole was also used. To calculate each intervention's CVI, values three and four were added by experts and the result was divided by the maximum score attributable to the intervention. The overall CVI was determined by adding the $C V I$ of the instrument's interventions, dividing the result by the total number of interventions. $A C V I \geq 0.78^{(17)}$ and, for the instrument as a whole, overall CVI $\geq 0.90$ were adopted as valid values for the interventions ${ }^{(18)}$.
In data analysis, the proportion of average and universal agreement was also calculated, which required another calculation of CVI from a dichotomized scale with the "relevant" (combining values 3 and 4) and "not relevant" answer options (grouping values 1 and 2) for each intervention. The number of experts who judged each intervention to be relevant was divided by the total number of experts, resulting in the intervention's CVI. The proportion of average agreement was calculated by adding each intervention's CVI and dividing the result by the number of interventions. To obtain universal agreement, the number of interventions considered relevant by all experts in the evaluation of all criteria was divided by the total interventions ${ }^{(19)}$. Valid average and universal agreement ratios of at least 0.90 and 0.80 , respectively, were adopted, which correspond to an excellent agreement among experts ${ }^{(17)}$.

Furthermore, Fleiss' Kappa coefficient for multiple experts was used, considering that values $<0.40$ indicate poor agreement; from 0.40 to 0.59 , reasonable agreement; from 0.60 to 0.74 , good agreement; from 0.75 to 1.00 , excellent agreement. Negative values indicate expert agreement less than chance (disagreement).

The 'irr' package was used for calculation. Although Fleiss' Kappa coefficient seems to be an improved measure of agreement over proportional agreement, its interpretation can be difficult, as it is sensitive to the number of observations made, data distribution and bias among observers ${ }^{(20)}$. Therefore, in this study, data were also analyzed using CVI, medium and universal agreement proportions.

\section{RESULTS}

Of the total number of participants $(n=40)$, female experts stood out $(n=36 ; 90 \%)$. The mean age was 44.9 years, with a standard deviation of 7.75 years. The minimum age observed was 30 years, and the maximum, 64 years. As for nationality, there was a Brazilians figured prominently ( $n=25 ; 62.5 \%)$, followed by Peruvians $(n=7$; $17.5 \%)$. More than half ( $n=23 ; 57.5 \%$ ) completed specialization in intensive care; 10 (25\%) had a doctoral degree; five (12.5\%) had a master's degree; two (5\%) had postdoctoral degrees.

Teaching ( $n=12 ; 30 \%)$ stood out among the professions, followed by teaching in care $(n=8 ; 20 \%)$, and teaching only in management $(n=4 ; 10 \%)$. Most $(n=29 ; 72.5 \%)$ had more than 10 years of work in ICUs, nine (22.5\%), from 6 to 10 years, and two (5\%) worked from 1 to 5 years.

The results of the instrument's content validation are presented in two groups: foreign and Brazilian experts. In the criteria analysis, six interventions $(4,13,15,20.21$ and 25$)$ presented CVI lower than the recommended $(<0.78)$ in at least one criterion, according to the assessment of Brazilian or foreign experts (Table1).

However, in general, only two interventions (15 and 25) did not reach a valid CVI $(\geq 0.78)$, when considering the set of criteria. Both interventions reached CVI 0.77 in the assessment of foreign and Brazilian experts, respectively (Table 1). The instrument's overall CVI was 0.91 after assessment of the two groups of experts (Table 1), indicating that it is relevant, representing the content "unplanned extubation prevention in Intensive Care Units" for application in Brazil and other Latin countries such as Peru, Chile, Uruguay, Paraguay, and Argentina. 
Table 1 - Content validation of a care instrument for unplanned extubation prevention in Intensive Care Units by Brazilian and foreign nurses, Florianópolis, Santa Catarina, Brazil, 2017

\begin{tabular}{|c|c|c|c|c|c|c|c|c|c|c|c|c|c|}
\hline Nursing Interventions & $\begin{array}{l}\text { REL } \\
\text { CVI }\end{array}$ & $\begin{array}{l}\text { CON } \\
\text { CVI }\end{array}$ & & & $\begin{array}{l}\text { O } \\
\text { C }\end{array}$ & $\begin{array}{l}B J \\
V I\end{array}$ & $\begin{array}{l}\text { SI } \\
\text { C }\end{array}$ & $\begin{array}{l}M \\
\text { VI }\end{array}$ & $\begin{array}{l}\mathrm{FE} \\
\mathrm{C}\end{array}$ & & $\begin{array}{l}\text { ACC } \\
\text { CV }\end{array}$ & & $\begin{array}{c}\text { CVI } \\
\text { interventions }\end{array}$ \\
\hline & BN FE & BN FE & BN & FE & BN & FE & BN & FE & BN & FE & BN & FE & BN FE \\
\hline
\end{tabular}

Agitation/delirium/pain management

1. Detecting delirium using validated scales: ICDSC or CAM-ICU.

2. Assessing pain with BPS.

$\begin{array}{llllllllllllllll}0.98 & 0.98 & 0.94 & 0.97 & 0.88 & 0.92 & 0.85 & 0.97 & 0.78 & 0.92 & 0.82 & 0.95 & 0.86 & 0.93 & 0.87 & 0.95\end{array}$

$\begin{array}{llllllllllllllll}0.99 & 0.93 & 0.95 & 0.93 & 0.89 & 0.90 & 0.87 & 0.93 & 0.79 & 0.88 & 0.82 & 0.85 & 0.86 & 0.83 & 0.88 & 0.89\end{array}$

3. Monitoring the level of sedation and agitation with RASS

$\begin{array}{llllllllllllllll}0.99 & 0.97 & 0.95 & 0.90 & 0.92 & 0.98 & 0.91 & 1.00 & 0.89 & 0.92 & 0.87 & 0.98 & 0.93 & 0.97 & 0.92 & 0.96\end{array}$

4. Useing standardized protocol for assessment and management of pain, agitation, delirium.

5. Maintaining continuous surveillance of patients during bathing, transportation, changing positions and in the weaning process.

6. Identifying and modifying non-pharmacological risk factors for developing delirium.

7. Using mechanical restraint in appropriate clinical situations assessed by the team and based on current legislation.

8. Detecting asynchrony during mechanical ventilation.

$\begin{array}{llllllllllllllll}0.96 & 1.00 & 0.90 & 0.98 & 0.94 & 1.00 & 0.95 & 0.98 & 0.88 & 1.00 & 0.99 & 0.97 & 0.70 & 0.92 & 0.90 & 0.98\end{array}$

$\begin{array}{llllllllllllllll}0.95 & 0.85 & 0.95 & 0.90 & 0.96 & 0.92 & 0.96 & 0.88 & 0.94 & 0.92 & 0.98 & 0.88 & 0.98 & 0.90 & 0.96 & 0.89\end{array}$

$\begin{array}{llllllllllllllll}0.89 & 0.87 & 0.93 & 0.92 & 0.96 & 0.98 & 0.89 & 0.90 & 0.82 & 0.97 & 0.83 & 0.92 & 0.86 & 0.88 & 0.88 & 0.92\end{array}$

$\begin{array}{llllllllllllllll}0.95 & 0.83 & 0.89 & 0.92 & 0.96 & 0.97 & 0.97 & 0.90 & 0.93 & 0.90 & 0.96 & 0.93 & 0.96 & 0.92 & 0.95 & 0.91\end{array}$

$\begin{array}{llllllllllllllll}0.93 & 0.87 & 0.98 & 0.92 & 0.94 & 0.82 & 0.96 & 0.85 & 0.82 & 0.87 & 0.94 & 0.93 & 0.89 & 0.87 & 0.92 & 0.88\end{array}$

Respiratory device stability

9. Using standardized technique and material when fixing an OTT.

$\begin{array}{llllllllllllllll}0.94 & 0.95 & 0.91 & 0.97 & 0.97 & 0.93 & 0.97 & 0.98 & 0.97 & 0.98 & 0.99 & 0.97 & 0.97 & 0.95 & 0.96 & 0.96\end{array}$

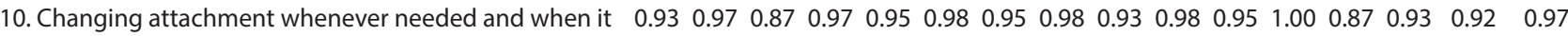
is evidently damaged.

11. Checking cuff pressure, keeping $20-30 \mathrm{~cm}$ of $\mathrm{H} 2 \mathrm{O}$.

$\begin{array}{llllllllllllllll}0.91 & 0.85 & 0.92 & 0.95 & 0.97 & 0.98 & 0.94 & 0.90 & 0.99 & 0.98 & 0.91 & 0.98 & 0.94 & 0.90 & 0.94 & 0.93\end{array}$

12. Monitoring OTT numbering at the level of the labial commissure.

13. Assessing OTT positioning with chest X-ray.

$\begin{array}{llllllllllllllll}0.98 & 0.97 & 0.98 & 0.98 & 0.94 & 1.00 & 0.95 & 0.93 & 0.98 & 1.00 & 0.99 & 1.00 & 0.99 & 0.98 & 0.97 & 0.98\end{array}$

14. Performing MV pulmonary auscultation and checking lung expansion.

15. Assessing OTT permeability through the progression of aspiration probe and the presence of respiratory effort.

16. Checking changes in the capnograph curve.

17. Avoiding pulling OTT through the MV circuit, and positioning the circuit carefully during bathing, changing positions and transport.

18. Center the patients' head during bathing, changing positions and transport.

$\begin{array}{llllllllllllllll}0.93 & 0.75 & 0.91 & 0.73 & 0.94 & 0.88 & 0.95 & 0.77 & 0.98 & 0.88 & 0.90 & 0.80 & 0.98 & 0.82 & 0.94 & 0.80\end{array}$

$\begin{array}{llllllllllllllll}0.98 & 0.83 & 0.97 & 0.85 & 0.98 & 0.92 & 0.93 & 0.85 & 0.91 & 0.90 & 0.96 & 0.90 & 0.95 & 0.92 & 0.95 & 0.88\end{array}$

$\begin{array}{llllllllllllllll}0.88 & 0.60 & 0.86 & 0.72 & 0.86 & 0.87 & 0.92 & 0.73 & 0.92 & 0.88 & 0.91 & 0.85 & 0.90 & 0.75 & 0.89 & 0.77\end{array}$

$\begin{array}{llllllllllllllll}0.87 & 0.80 & 0.88 & 0.90 & 0.89 & 0.95 & 0.92 & 0.87 & 0.92 & 0.88 & 0.88 & 0.92 & 0.93 & 0.88 & 0.90 & 0.89\end{array}$

$\begin{array}{llllllllllllllll}0.97 & 0.98 & 0.97 & 1.00 & 0.99 & 0.98 & 0.96 & 0.98 & 0.98 & 0.98 & 0.99 & 0.98 & 0.94 & 0.95 & 0.97 & 0.98\end{array}$

$\begin{array}{llllllllllllllll}0.87 & 0.82 & 0.89 & 0.85 & 0.94 & 0.85 & 0.88 & 0.80 & 1.00 & 0.92 & 0.99 & 0.82 & 0.95 & 0.87 & 0.93 & 0.85\end{array}$

Weaning from sedation and spontaneous breathing

assessment

19. Stoping using sedatives daily using standardized protocols.

20. Using the spontaneous wake-up test.

21. Using the spontaneous breathing test.

22. Assessing daily the need for early weaning.

23. Monitoring alarms related to airway pressure and graphical analysis of volume-time, flow-time and pressure curves.

Human resource management

24. Maintaining enough nur. Staff per patient in critical health situation according to workload.

25 . Determining nur. sizing according to the technical standards in force in each institution.

26. Conducting/providing continuing education and training for nur. staff.

All interventions

$\begin{array}{llllllllllllllll}0.81 & 0.93 & 0.83 & 0.90 & 0.85 & 0.98 & 0.81 & 0.95 & 0.94 & 0.93 & 0.93 & 0.90 & 0.92 & 0.93 & 0.87 & 0.93\end{array}$

$\begin{array}{llllllllllllllll}0.91 & 0.87 & 0.95 & 0.88 & 0.88 & 0.86 & 0.85 & 0.88 & 0.77 & 0.87 & 0.77 & 0.83 & 0.85 & 0.88 & 0.85 & 0.87\end{array}$ $\begin{array}{llllllllllllllll}0.93 & 0.92 & 0.95 & 0.90 & 0.88 & 0.83 & 0.85 & 0.92 & 0.77 & 0.85 & 0.77 & 0.85 & 0.85 & 0.90 & 0.86 & 0.88\end{array}$ $\begin{array}{llllllllllllllll}0.89 & 0.98 & 0.85 & 0.98 & 0.93 & 0.97 & 0.88 & 0.98 & 0.96 & 0.95 & 0.97 & 0.93 & 0.96 & 0.95 & 0.92 & 0.96\end{array}$ $\begin{array}{lllllllllllllllll}0.93 & 0.82 & 0.92 & 0.82 & 0.93 & 0.95 & 0.91 & 0.88 & 0.89 & 0.87 & 0.97 & 0.85 & 0.96 & 0.80 & 0.93 & 0.86\end{array}$

$\begin{array}{llllllllllllllll}0.94 & 0.97 & 0.86 & 0.92 & 0.88 & 0.97 & 0.87 & 0.98 & 0.93 & 0.87 & 0.88 & 0.88 & 0.87 & 0.95 & 0.89 & 0.93\end{array}$ $\begin{array}{llllllllllllllll}0.74 & 0.98 & 0.71 & 0.90 & 0.80 & 0.97 & 0.79 & 0.92 & 0.79 & 0.88 & 0.86 & 0.97 & 0.70 & 0.97 & 0.77 & 0.94\end{array}$ $\begin{array}{llllllllllllllll}0.95 & 0.95 & 0.91 & 0.92 & 0.95 & 1.00 & 0.92 & 0.97 & 0.88 & 0.87 & 0.90 & 0.95 & 0.96 & 0.97 & 0.92 & 0.95\end{array}$ $\begin{array}{llllllllllllllll}0.92 & 0.89 & 0.91 & 0.91 & 0.92 & 0.94 & 0.91 & 0.91 & 0.90 & 0.92 & 0.91 & 0.92 & 0.91 & 0.90 & 0.91 & 0.91\end{array}$

Note: REL - Relevance; CON - Consistency; CLA - Clarity; OBJ - Objectivity; SIM - Simplicity; FEA - Feasibility; ACCU - Accuracy; CVI - Content Validity Index; BN - Brazilian Nurses; FE - Foreign Nurses; ICDS - Intensive Care Delirium Screening Checklist; CAM-ICU - Confussion Assessment Method for the ICU; BPS - Behavioral Pain Scale; RASS - Richmond Agitation Sedation Scale; OTT - Orotracheal Tube; Rx - Radiography; VM - Vesicular Murmur; MV - Mechanical Ventillation; nur. - nursing.

T.N. - this instrument was freely translated, as it has not been validated in English yet. 
The experts'suggestions/recommendations made it possible to adapt the instrument's content. Changes related to grammar and vocabulary were made to improve the clarity of expressions. There was an agglutination of interventions in the components: Agitation/ delirium/pain management and Respiratory device stability (Chart 1).

Chart 1 - Instrument adjustments by care components according to the experts' suggestions/recommendations, Florianópolis, Santa Catarina, Brazil, 2017

\section{Adjustments performed}

Component: Agitation/delirium/pain management

Interventions 1, 2 and 3 were combined.

The Ramsay Scale was added to intervention 3, joined to 1 and 2 .

The verb "detect" was changed to "identify" in intervention 6 .

Non-pharmacological risk factors for delirium development in

intervention 6 were mentioned.

The term "evaluation" was eliminated and "institutional" was inserted in the intervention 4.

"Maintain continuous surveillance" was replaced by "continuously monitor" in intervention 5.

"Modify" was changed to "prevent" in intervention 6.

\section{Component: Respiratory device stability}

Interventions 9 and 10 were combined into one.

In intervention 10, the situation in which OTT fixation should be

changed was changed, so that it occurs once per shift according to

skin conditions.

"Adventitious noises" was added in intervention 14, and it was specified that it should be performed at least once per shift.

The verb "check" was replaced by "detect" and "capnograph" by "capnography" in intervention 16.

Interventions 17 and 18 were combined and synthesized.

Component: Weaning from sedation and spontaneous breathing assessment

The writing was changed to "use a standardized protocol to stop the use of sedatives" in intervention 19.

The test was specified to assess patients' awakening and that it should be used after suspending sedatives using the RASS or Ramsay Scale in intervention 20.

The spontaneous breathing test was explained using T-tube in intervention 21.

The word "need" was changed to "possibility" in intervention 22, and it was specified that standard protocols should be used in this intervention.

\section{Component: Human resource management}

The component's name was changed to "in-service education".

The term "continued" was replaced by "permanent" and the words

"provide" and "training" were excluded from intervention 26.

Note: RASS - Richmond Agitation Sedation Scale; Ramsay - Ramsay Sedation Scale; OTT Orotracheal Tube.

Regarding universal agreement among experts, an agreement of 0.040 (4.0\%) was identified among Brazilians and 0.266 (26.6\%) among foreigners, configuring a better agreement in the latter group. The average agreement on interventions was also better among foreign experts (87.6\%), when compared to Brazilians (82.4\%), values very close to those established for an excellent agreement (90\%) among experts.

Fleiss' Kappa coefficient indicated absence or weak agreement among Brazilian experts ( $\mathrm{k}-0.034$ to 0.065 ) and among foreigners ( $\mathrm{k}-0.067$ to 0.067 ) for the isntrument's four care components, considering the seven evaluated criteria. This may have occurred because this coefficient is sensitive to the number of observations made, since 26 interventions were assessed by 25 Brazilian experts and 15 foreigners.
Of the 26 interventions (Chart 1), two (interventions 4 and 25) were excluded only from the Brazilian version, and one (intervention 13) from the foreign one, for presenting $\mathrm{CVI}<0.78$ in the assessment by Brazilian and foreign experts. We opted to exclude four other interventions $(8,11,12$ and 23). No scientific evidence was found to support their implementation in UPE prevention, although classified when the instrument was built by GRADE with a strong recommendation, which made them considered for the validation process. Intervention 15 was eliminated for both reasons.

Another seven interventions were combined (interventions 1 and 2 joined 3; 9 joined 10 ; and 17 joined 18 ), reducing to a total of three. Although interventions 20 and 21 were evaluated by Brazilian experts with CVI 0.77 , they were maintained in the final version after taking into account the suggestions for adjustments that emerged from the validation process.

Chart 2 - Final version of the nursing care instrument for unplanned extubation prevention in Intensive Care Units, Florianópolis, Santa Catarina, Brazil, 2017

\begin{tabular}{l} 
Components and Interventions \\
\hline Component: Agitation/delirium/pain management \\
\hline 1 - Identify and evaluate delirium with the ICDSC or CAM-ICU scales, \\
pain with the behavioral pain scale - BPS, and the level of sedation and \\
agitation with the RASS or RAMSAY scale. \\
2 - Using standardized institutional protocol for pain, agitation and de- \\
lirium management. * \\
3 - Monitoring patients continuously during bathing, transportation, \\
changing positions and in the weaning process. \\
4 - Identifying and preventing non-pharmacological risk factors for \\
developing delirium, such as noise, isolation, lack of communication, \\
sleep deprivation, visit deprivation, absence of daylight, physical re- \\
straint and late mobilization. \\
5 - Useing mechanical restraint in appropriate clinical situations, as- \\
sessed by the team and based on current legislation. \\
\hline Component: Respiratory device stability \\
\hline 6 - Performing OTT fixation replacement using standardized technique \\
and material, once per shift according to the skin conditions around \\
OTT/faces. \\
7 - Assessing OTT positioning with chest X-ray. ** \\
8 - Identifying the presence of adventitious sounds, breath sounds and \\
lung expansion, at least once per shift. \\
9 - Detecting changes in capnography curves. \\
10 - Avoiding moving the OTT through the MV circuit, position the cen- \\
tralized breathing device carefully during bath, changing its position, \\
transporting and changing its fixation. \\
-
\end{tabular}

Component: Weaning from sedation and spontaneous breathing assessment

11 - Using standardized protocol to stop using sedatives.

12 - Using the SAT test to assess patients' awakening, after suspending sedatives, using the RASS or RAMSAY scale.

13 - Using the spontaneous breathing SBT test, using the T-tube.

14 - Assessing daily the possibility of early weaning, using standardized protocols.

Component: Human resource management

15 - Maintaining a sufficient number of nursing staff per patient in a critical health situation, according to the workload.

16 - Determining nursing staff sizing according to the technical standards in force in each institution.*

17 - Carrying out nursing staff permanent education.

Note: ICDS - Intensive Care Delirium Screening Checklist; CAM-ICU - Confussion Assessment Method for the ICU; BPS - Behavioral Pain Scale; RASS - Richmond Agitation Sedation Scale; RAMSAY Ramsay Sedation Scale; OTT-Orotracheal Tube; MV-Mechanical Ventillation; SAT-Spontaneous Awakening Trial; SBT-Spontaneous Breathing Trial; Rx-Radiography; *Intervention eliminated from the Brazilian version instrument; **Intervention suppressed from the foreign version instrument. T.N. - this instrument was freely translated, as it has not been validated in English yet. 
Thus, the instrument includes four components of care and their respective interventions, totaling 16 in the foreign version and 15 in the Brazilian version: Agitation/delirium/pain management (five and four interventions, respectively); Respiratory device stability (four and five interventions, respectively); Weaning from sedation and spontaneous breathing assessment (four interventions); Human resource management (three and two interventions, respectively). The difference in the total number of interventions between the Brazilian and foreign versions resulted from the validation process. Brazilian and foreign experts judged all interventions differently.

All interventions maintained in the final version (Chart 2) have a high or moderate level of evidence and a strong strength of recommendation. This version has specificities for application in Brazil and abroad, considering the assessment by experts.

\section{DISCUSSION}

The profile of nurse judges was characterized by being women, with graduate and ICU experience for more than 10 years. These results coincide with a survey in which it was identified that most nurses were female, with an average age of 32.7 , and concluded their graduate studies ${ }^{(21)}$.

As for the instrument to prevent UPE in ICUs, a CVI of 0.91 was obtained, in line with the scientific literature ${ }^{(17-22)}$. As presented in the results, after content validation by the experts, the instrument was subjected to some restructuring/adjustments. In the first component (Agitation/delirium/pain management), both groups of experts judged interventions with a high CVI.

In the first intervention, identification of delirium, agitation and pain was synthesized, considering placing the CAM-ICU, ICSDC, RASS, CPOT and BPS (23) detection scales, which have high levels of reliability and validity, in addition to being available in Portuguese and Spanish. It was considered convenient to add Ramsay scale, as it is a scale widely used in practice, having a strong correlation with the RASS scale and easy applicability ${ }^{(24)}$.

A national study aiming at identifying the level of sedation and its association with AE as accidental extubation found that patients with mild sedation have a greater number of $A E$ after sedation shutdown. In the case of sedated patients, the lack of sensory perception makes them deserve better attention in relation to $A E$ occurrence ${ }^{(25)}$.

Although the intervention "Using standardized institutional protocol for pain, agitation and delirium management" was maintained only in the foreign version for consistency with the experts' assessment, it is relevant in the assessment and critical management of patients at the bedside. Clinical Practice Guidelines for the Prevention and Management of Pain, Agitation/Sedation, Delirium, Immobility, and Sleep Disruption in Adult Patients in the $I C U^{(26)}$, recently updated, support the importance of implementing standardized protocols based on the best evidence in order to to guide clinical practice in the critical care setting.

Regarding continuous monitoring of patients during bathing, transportation, change of decubitus and weaning process, a study showed that the increased risk of UPE during bed bathing, sedation weaning and decubitus change must be considered and preventive measures must be taken ${ }^{(25)}$.
Regarding the intervention "Identifying and modifying nonpharmacological risk factors for developing delirium", conditions such as noise, excessive artificial light, absence of visits, immobility, lack of sleep, poor communication, among others, increase and worsen delirium, pain and anxiety, creating discomfort and increasing the possibility of UPE(27-28). A systematic review and meta-analysis showed that non-pharmacological interventions were effective in reducing the length and occurrence of delirium in critically ill patients ${ }^{(29)}$.

As for mechanical restraint, there are still many controversies about its recommendation, as well as the relationship between its use and delirium in ICUs; however, studies suggest that this practice be evaluated by the unit's team, based on institutional and ethical regulations ${ }^{(30)}$. A research conducted in Japan showed that $75 \%$ of MV patients were subjected to physical restraint, suggesting the need for a systematic approach for this procedure to be performed judiciously ${ }^{(31)}$. Therefore, the nursing staff must maximize the care for patients who need restraint and, especially, the valuation of the sensory and skin care as well as contain it for the shortest possible time ${ }^{(32)}$.

Thus, in relation to the component "Respiratory device stability", experts validated the interventions' content with CVI values between 0.80 and 1.00. Inadequate fixation of OTT is one of the most signalized procedures in the literature, associated with the occurrence of UPE ${ }^{(3,33)}$. Researches that address safety in the fixation of respiratory devices and their relationship with UPE have been developed ${ }^{(33-34)}$, and it is known that UPE occurs mainly during the bath, at the time of lateralization of the body, and this is explained loss of centralization of the head ${ }^{(35)}$. A review study concluded that UPE can have serious consequences for patients, since reintubation is usually necessary ${ }^{(36)}$.

The interventions to assess OTT positioning were to perform pulmonary auscultation of adventitious sounds and to detect changes in the capnograph curve. These measures facilitate verifying the tube's correct location, allowing the monitoring of specific parameters to check displacements and changes in the airway ${ }^{(37-38)}$.

There was disagreement between Brazilian and foreign experts in relation to the intervention "Assessing OTT positioning with chest X-ray", which justifies the presentation of this only in the Brazilian version of the instrument. Foreign experts deemed this intervention unnecessary and unspecific, in addition to considering that there are other faster and more effective methods for monitoring OTT positioning.

The scientific literature corroborates that using chest radiography has been discouraged as a standard to check OTT positioning due to the time and need for more specialized training, and its use at the bedside is not feasible ${ }^{(39)}$. Although bedside chest radiography in intensive care poses an additional risk of accidental extubation, as it requires patients to be lifted by a professional to place the X-ray plate at the level of the chest, its daily use provides the team with a strict control of OTT positioning $^{(40)}$; this may justify the evaluation of Brazilian experts. To avoid UPE caused by this intervention, nurses staying at the bedside to guide the head is essential(40).

Interventions, such as positioning the patients' head and MV circuits, were considered in the instrument from the perspective 
of UPE incidence in moments of extension, flexion and rotation of the head during the change of position, bed bath and transportation ${ }^{(25)}$. Thus, MV circuits cause tractive forces during these procedures and, therefore, can conduct UPE ${ }^{(41)}$.

Concerning the component "Weaning from sedation and spontaneous breathing assessment", it appears that nurses play a crucial role considering the criteria established in the final version. Assessing sensory, level of sedation and clinical progression by these professionals leads to interdisciplinary decision making for weaning from $\mathrm{MV}^{(42)}$, guided interruption of sedation and conducting awakening tests such as Spontaneous Awakening Trial (STA) and Spontaneous Breathing Trial (SBT). Such tests are recommended because they are parameters that verify the capacity and autonomy in patients' spontaneous breathing ${ }^{(43)}$.

Interventions aimed at weaning, presented in the final version of the proposed instrument, refer to using standardized protocols. On this subject, a study maintains that the implementation of standardized weaning protocols should be promoted, with a view to improving the quality of care and ensuring the comfort of intubated patients ${ }^{(7)}$. Standardized weaning protocols were associated with a lower incidence of UPE, and its use is viable for promoting compliance among professionals in patient care, when the protocols are clinically prescribed ${ }^{(44)}$.

It should be noted that, applying spontaneous breathing test by nursing was considered in the instrument, since this procedure is performed by nurses in units where there are no physiotherapists, or the care of this professional still occurs part time.

Concerning the component "in-service education", a study carried out in France identified that high workload of nurses is a risk factor for UPE occurrence, among other AE in ICUs ${ }^{(45)}$. A proper nursing staff sizing, on the other hand, directs care and promotes higher quality of care and patient safety ${ }^{(46)}$. Another important issue refers to profesional permanent education, in the sense of providing them with daily tools to develop safe practices based on scientific evidence ${ }^{(47)}$.

Although the intervention "Determining nursing sizing according to the technical standards in force in each institution" is not in the final version of the Brazilian instrument, which is in compliance with expertts' assessment in the country, an inadequate proportion of nurses/patients is a factor that increases the risk of UPE ${ }^{(7)}$. Nursing staff sizing in services, including for intensive care, is supported by Resolution 543/2017 of the Federal Nursing Council (Conselho Federal de Enfermagem) ${ }^{(48)}$.

Finally, it is still necessary to analyze the difference in medium and universal agreement proprortions between Brazilian and foreign experts after assessing the instrument's content, a difference that may be related to the number of experts, different between the two groups. The larger sample of Brazilian experts revealed lower medium and universal agreement proportions, when compared to foreigners. It is noteworthy that the more experts included in the assessment, the greater the likelihood of lower agreement values among them ${ }^{(18)}$.

\section{Limitations of the study}

A limitation to the study was the fact that building thisinstrument involved only a group of professionals. The interdisciplinary team's view to build instruments for interventions in care enables an integrated approach in strategies for patient safety related to airway care in ICU.

\section{Contributions to nursing}

The evaluated instrument has the potential to contribute to reduce UPE and promote patient safety in intensive care, in addition to serving as a reference tool in permanent education programs in caring for patients with MV and in the process of weaning from ventilation. Therefore, this study has as an implication for nursing research assessment of the instrument implementation in care practice, in order to identify its weaknesses, potentialities and contributions to UPE prevention. In care, it implies permanent education of nurses to use the instrument properly and safely in care for mechanically ventilated patients.

\section{CONCLUSIONS}

The instrument evaluated by experts from six countries in South America is relevant and represents the content "unplanned extubation prevention in an Intensive Care Unit"; it can be implemented in Brazil and in Latin countries, in the Brazilian and foreign versions, respectively, consisting of 14 and 16 interventions, distributed in the following care components: agitation/delirium/pain management; respiratory device stability; weaning from sedation and spontaneous breathing assessment; in-service education.

Further clinical validation studies are suggested, as well as cross-cultural adaptation, to adjust the instrument to different linguistic and socio-cultural contexts of care.

\section{FUNDING}

This research was supported by the Coordination for the Improvement of Higher Education Personnel (CAPES - Coordenação de Aperfeiçoamento de Pessoal de Nível Superior), award number 001.

\section{REFERENCES}

1. Ribeiro GSR, Silva RC, Ferreira MA. Technologies in intensive care: causes of adverse events and implications to nursing. Rev Bras Enferm [Internet]. 2016 [cited 2020 Apr 25];69(5):915-23. Available from: http://www.scielo.br/pdf/reben/v69n5/en_0034-7167-reben-69-05-0972.pdf

2. World Health Organization. Conceptual Framework for the International Classification for Patient Safety [Internet]. Geneva: World Health Organization; 2009. Available from: https://www.who.int/patientsafety/implementation/taxonomy/ICPS-report/en/

3. Lucchini A, Bambi S, Galazzi A, Elli S, Negrini C, Vaccino S, et al. Unplanned extubations in general intensive care unit: a nine-year retrospective analysis. Acta Biomed [Internet]. 2018 [cited 2020 Apr 25];89(7-S):25-31. Available from: https://www.ncbi.nlm.nih.gov/pubmed/30539936 
4. Cosentino C, Fama M, Foà C, Bromuri G, Giannini S, Saraceno M, et al. Unplanned Extubations in Intensive Care Unit: evidences for risk factors: a literature review. Acta Biomed [Internet]. 2017 [cited 2020 Apr 25];30;88(5S):55-65. Available from: https://www.ncbi.nlm.nih.gov/ pubmed/29189706

5. Chuang ML, Lee CY, Chen YF, Huang SF, Lin IF. Revisiting unplanned endotracheal extubation and disease severity in intensive care. PLoS ONE [Internet]. 2015 [cited 2020 Apr 25];10:e0139864. Available from: https://www.ncbi.nlm.nih.gov/pmc/articles/PMC4617893/pdf/ pone.0139864.pdf

6. González-Castro A, Peñasco Y, Blanco C, González-Fernández C, Domínguez MJ, Rodríguez-Borreján JC. Unplanned extubation in ICU, and the relevance of non-dependent patient variables the quality of care. Rev Calid Asist [Internet]. 2014 [cited 2020 Nov 30];29(6):334-40. Available from: https://www.sciencedirect.com/science/article/pii/S1134282X14001195

7. Danielis M, Chiaruttini S, Palese A. Unplanned extubations in an intensive care unit: findings from a critical incident technique. Intensive Crit Care Nurs [Internet]. 2018 [cited 2020 Apr 25];47:69-77. Available from: https://www.sciencedirect.com/science/article/pii/ S0964339718300995?via\%3Dihub

8. Oliveira RM, Leitão IMTA, Silva LMS, Figueiredo SV, Sampaio RL, Gondim MM. Strategies for promoting patient safety: from the identification of the risks to the evidence-based practices. Esc Anna Nery [Internet]. 2014 [cited 2020 Apr 25];18(1):122-9. Available from: http://www. scielo.br/pdf/ean/v18n1/en_1414-8145-ean-18-01-0122.pdf

9. Leite SS, Áfio ACE, Carvalho LV, Silva JM, Almeida PC, Pagliuca LMF. Construction and validation of an Educational Content Validation Instrument in Health. Rev Bras Enferm [Internet]. 2018 [cited 2020 Apr 25];71(Suppl 4):1635-41. Available from: http://www.scielo.br/pdf/ reben/v71s4/0034-7167-reben-71-s4-1635.pdf

10. Silva RDN, Rosa LM, Radünz V, Cesconetto D. Evaluation and classification of vaginal stenosis in brachytherapy: instrument content validation for nurses. Texto Contexto Enferm [Internet]. 2018 [cited 2020 Apr 26];27(2):e5700016. Available from: https://www.scielo.br/pdf/ tce/v27n2/en_0104-0707-tce-27-02-e5700016.pdf

11. Gelvez-Zapata S, D'Oliveiro R, Osgathorpe J, Lonsdale J, Petty M, Jones N. Introduction of the unplanned extubations bundle in a tertiary cardiothoracic critical care unit: does it make any difference? Intensive Care Medicine Experimental [Internet]. 2015 [cited 2020 Apr 25];3(Suppl 1):A938. Available from: http://www.icm-experimental.com/content/3/S1/A938

12. Fontánez-Nieves TD, Frost M, Anday E, Davis D, Cooperberg D, Carey AJ. Prevention of unplanned extubations in neonates through process standardization. J Perinatol [Internet]. 2016 [cited 2020 Apr 25];36(6):469-73. Available from: https://www.nature.com/articles/jp2015219

13. Guimarães QCP, Pena SB, Lopes JDE, Lopes CT, Barros ALBT. Experts for validation studies in nursing: new proposal and selection criteria. Int J Nurs Knowl [Internet]. 2016 [cited 2020 Apr 25];27(3):130-5. Available from: https://onlinelibrary.wiley.com/doi/epdf/10.1111/2047-3095.12089

14. GRADE working group. Grading of Recommendations Assessment, Development and Evaluation - GRADE. What is GRADE? [Internet]. 2020[cited 2020 Apr 25]. Available from: http://www.gradeworkinggroup.org/

15. Assunção IKFC, Medeiros LP, Dias TYAF, Salvetti MG, Dantas DV, Torres GV. Protocol validation for people with venous ulcers: a quantitative study. Online Braz J Nurs [Internet]. 2016 [cited 2020 Apr 25];15(2):226-35. Available from: http://www.objnursing.uff.br/index.php/nursing/ article/view/5251

16. Vituri DW, Matsuda LM. Content validation of quality indicators for nursing care evaluation. Rev Esc Enferm USP [Internet]. 2009 [cited 2020 Apr 25];43(2):429-37. Available from: http://www.scielo.br/pdf/reeusp/v43n2/en_a24v43n2.pdf

17. Polit DF, Beck CT, Owen SV. Is the CVI an acceptable indicator of content validity? Appraisal and recommendations. Res Nurs Health [Internet]. 2007 [cited 2020 Apr 25]; 30(4):459-67. Available from: http://file.qums.ac.ir/repository/snm/Appraisal\%20and\%20 Recommendations\%202007.pdf

18. Polit DF, Beck CT. The Content Validity Index: are you sure you know what's being reported? Critique and recommendations. Res Nurs Health [Internet]. 2006 [cited 2020 Apr 25];29(5):489-97. Available from: https://www.ncbi.nlm.nih.gov/pubmed/16977646

19. Zamanzadeh V, Rassouli M, Abbaszadeh A, Majd HA, Nikanfar A, Ghahramanian A. Details of content validity and objectifying it in instrument development. Nurs Pract Today [Internet]. 2014 [cited 2020 Apr 25];1(3):163-71. Available from: http://npt.tums.ac.ir/index.php/npt/article/view/24

20. Wynd CA, Schmidt B, Schaefer MA. Two quantitative approaches for estimating content validity. West J Nurs Res [Internet]. 2003 [cited 2020 Apr 25];25(5):508-18. Available from: https://www.ncbi.nlm.nih.gov/pubmed/12955968

21. Araujo MAN, Lunardi Filho WD, Alvarenga MRM, Oliveira RDO, Souza JC, Vidmantas S. Sociodemographic profile of nurses of the hospital network. J Nurs UFPE [Internet]. 2017 [cited 2020 Apr 25];11(Suppl. 11):4716-25. Available from: https://periodicos.ufpe.br/revistas/ revistaenfermagem/article/view/231214

22. Souza AC, Alexandre NMC, Guirardello EB. Psychometric properties in instruments evaluation of reliability and validity. Epidemiol Serv Saúde. 2017;26(3):649-59. doi: 10.5123/s1679-49742017000300022

23. Hernández-Tejedor A, Peñuelas O, Sirgo RG, Llompart-Pou JA, Palencia HE, Estella A, et al. Recommendations of the working groups from the Spanish Society of Intensive and Critical Care Medicine and Coronary Units (SEMICYUC) for the management of adult critically ill patients. Med Intensiva [Internet]. 2017 [cited 2020 Apr 25];41(5):285-305. Available from: https://www.sciencedirect.com/science/article/pii/ S2173572717300991

24. Namigar T, Serap K, Esra AT, Ozul O, Can OA, Aysel A, et al. The correlation among the Ramsay sedation scale, Richmond agitation sedation scale and Riker sedation agitation scale during midazolam-remifentanil sedation. Rev Bras Anestesiol [Internet]. 2017 [cited 2020 Apr 20];67(4):347-54. Available from: http://www.scielo.br/pdf/rba/v67n4/0034-7094-rba-67-04-0347.pdf 
25. Barbosa TP, Beccaria LM, Silva DC, Bastos AS. Association between sedation and adverse events in intensive care patients. Acta Paul Enferm [Internet]. 2018 [cited 2020 Apr 25];31(2):194-200. Available from: http://www.scielo.br/pdf/ape/v31n2/en_1982-0194-ape-31-02-0194.pdf

26. Devlin JW, Skrobik Y, Gélinas C, Needham DM, Slooter AJC, Pandharipande PP, et al. Clinical Practice Guidelines for the Prevention and Management of Pain, Agitation/Sedation, Delirium, Immobility, and Sleep Disruption in Adult Patients in the ICU. Crit Care Med [Internet]. 2018 [cited 2020 Aug 11];46(9): e825-e873. Available from: https://pubmed.ncbi.nlm.nih.gov/30113379/

27. Herling SF, Greve IE, Vasilevskis EE, Egerod I, Bekker Mortensen C, Møller AM, et al. Interventions for preventing intensive care unit delirium in adults (Review). Cochrane Database Syst Rev[Internet]. 2018 [cited 2020 Apr 25];23(11):CD009783. Available from: https://www.ncbi.nlm. nih.gov/pmc/articles/PMC6373634/pdf/CD009783.pdf

28. Almeida TML, Azevedo LCP, Nosé PMG, Freitas FGR, Machado FR. Risk factors for agitation in critically ill patients. Rev Bras Ter Intensiva [Internet]. 2016 [cited 2018 Dec 20];28(4):413-9. Available from: http://www.scielo.br/pdf/rbti/v28n4/en_0103-507X-rbti-28-04-0413.pdf

29. Kang J, Lee M, Ko H, Kim S, Yun S, Jeong Y, et al. Effect of nonpharmacological interventions for the prevention of delirium in the intensive care unit: a systematic review and meta-analysis. J Crit Care [Internet]. 2018 [cited 2020 Apr 27];48:372-384. Available from: https://www. sciencedirect.com/science/article/pii/S0883944118310013?via\%3Dihub

30. Balci H, Arslan S. Nurses' information, attıtude and practices towards use of physical restraint in intensive care units. J Caring Sci [Internet]. 2018 [cited 2020 Apr 25];7(2)75-81. Available from: https://www.ncbi.nlm.nih.gov/pmc/articles/PMC6029653/pdf/jcs-7-75.pdf

31. Unoki T, Sakuramoto H, Ouchi A, Fujitani S. Physical restraints in intensive care units: a national questionnaire survey of physical restraint use for critically ill patients undergoing invasive mechanical ventilation in Japan. Acute Med Surg [Internet]. 2019 [cited 2020 Apr 28];6(1):68-72. Available from: https://www.ncbi.nlm.nih.gov/pmc/articles/PMC6328904/

32. Rose L, Burry L, Mallick R, Luk E, Cook D, Fergusson D, et al. Prevalence, risk factors, and outcomes associated with physical restraint use in mechanically ventilated adults. J Crit Care [Internet]. 2016 [cited 2020 Apr 25];31(1):31-5. Available from: https://www.sciencedirect.com/ science/article/pii/S0883944115004712?via\%3Dihub

33. Klugman D, Melton K, Maynord PO. Assessment of an unplanned extubation bundle to reduce unplanned extubations in critically ill neonates, infants, and children. JAMA Pediatr [Internet]. 2020 [cited 2020 Apr 25];13:e200268. Available from: https://jamanetwork.com/ journals/jamapediatrics/article-abstract/2764080

34. Landsperge JS, Byram JM, Lloyd BD. The effect of adhesive tape versus endotracheal tube fastener in critically ill adults: the endotracheal tube securement (ETTS) randomized controlled trial. Crit Care [Internet]. 2019 [cited 2020 Apr 25];23(1):161. Available from: https://ccforum. biomedcentral.com/articles/10.1186/s13054-019-2440-7

35. Lanzillotti LS, Seta MH, Andrade CL, Mendes Jr WV. Adverse events and other incidents in neonatal intensive care units. Rev Ciênc Saúde Coletiva. 2015;20(3):937-46. doi: 10.1590/1413-81232015203.16912013

36. Shin S, Park JH, Bae SH.Nurse staffing and nurse outcomes: a systematic review and metaanalysis. Nurs Outlook [Internet]. 2018 [cited 2020 Apr 25];66(3):273-82. Available from: https://www.nursingoutlook.org/article/S0029-6554(17)30265-8/fulltext

37. American College of Emergency Physicians. Verification of endotracheal tube placement. Ann Emerg Med. 2016;68:152. doi: 10.1016/j. annemergmed.2016.04.055

38. Silvestri S, Ladde JG, Brown JF et al. Endotracheal tube placement confirmation: 100\% sensitivity and specificity with sustained four-phase capnographic waveforms in a cadaveric experimental model. Resuscitation. 2017;192-98. doi: 10.1016/j.resuscitation.2017.01.002

39. Hossein-Nejad H, Payandemehr P, Bashiri SA, Nedai HH. Chest radiography after endotracheal tube placement: is it necessary or not? Am J Emerg Med. 2013;31(8):1181-2. doi: 10.1016/j.ajem.2013.04.032

40. Castellões TMFW, Silva LD. [Guideline for nursing care in the prevention of accidental extubation]. Rev Bras Enferm. [Internet]. 2007 [cited 2020 Jun 26]; 60(1): 106-109. Available from: https://www.scielo.br/pdf/reben/v60n1/a21v60n1.pdf Portuguese.

41. Chatterjee A, Kannaujia AK. Chatterjee A, Kannaujia AK. A novel technique for securing supra-glottic airway device to prevent mal-positioning. Indian J Anaesth [Internet]. 2016 [cited 2020 Apr 25]; 60(7): 521-22. Available from: https://www.ncbi.nlm.nih.gov/pmc/articles/PMC4966362/

42. Bardwell J, Brimmer S, Davis W. Implementing the ABCDE Bundle, Critical-Care Pain Observation Tool, and Richmond Agitation-Sedation Scale to Reduce Ventilation Time. AACN Adv Crit Care [Internet]. 2020 [cited 2020 Apr 25];31(1):16-21. Available from: https://www.ncbi. nlm.nih.gov/pubmed/32168511

43. Sosnowski K, Mitchell ML, White H, Morrison L, Sutton J, Sharratt J, et al. A feasibility study of a randomised controlled trial to examine the impact of the ABCDE bundle on quality of life in ICU survivors. Pilot Feasibility Stud [Internet]. 2018 [cited 2020 Apr 25]; 4:32. Available from: https://pilotfeasibilitystudies.biomedcentral.com/track/pdf/10.1186/s40814-017-0224-x

44. Jarachovic M, Mason M, Kerber K, McNett M. The role of standardized protocols in unplanned extubations in a medical intensive care unit. Am J Crit Care [Internet]. 2011 [cited 2020 Jun 26];20(4): 304-12. Available from: https://pubmed.ncbi.nlm.nih.gov/21724634/

45. Faisy C, Davagnar C, Ladiray D, Djadi-Prat J, Esvan M, Lenain E, et al. Nurse workload and inexperienced medical staff members are associated with seasonal peaks in severe adverse events in the adult medical intensive care unit: a seven-year prospective study. Int J Nurs Stud [Internet]. 2016 [cited 2020 Apr 25];62:60-70. Available from: https://www.ncbi.nlm.nih.gov/pubmed/27455207

46. Silva LC da, Oliveira DAL, Santos ABR, Barbosa MS, Araújo LG, Barboza MTV et al. Personel dimensioning and its interference in the quality of care. Rev Enferm UFPE [Internet]. 2019 [cited 2020 Apr 25];13(1):491-8. Available from: https://periodicos.ufpe.br/revistas/ revistaenfermagem/article/view/236551 
47. Vicente C, Amante LN, Santos MJ, Alvarez AG. Care for the person with oncological wound: permanent education in nursing mediated by educational technologies. Rev Gaúcha Enferm. 2019;40: e20180483. doi: 10.1590/1983-1447.2019.20180483

48. Conselho Federal de Enfermagem. Resolução Cofen n. 543/2017 [Internet]. 2017[cited 2020 Apr 25]. Available from: http://www.cofen.gov. br/resolucao-cofen-5432017_51440.html 